\title{
Research on power grid effective assets input-output evaluation based on super-efficient DEA model
}

\author{
An Lei $^{1}$, Lan Xinyi ${ }^{2}$,Wang Mianbin ${ }^{1}, L i$ Jinchao ${ }^{3, *}$ \\ ${ }^{1}$ State Power Economic Research Institute China State Grid Jibei Electric Power Company Limited, Beijing 102209, China \\ ${ }^{2}$ School of Economics and Management, North China Electric Power University, Beijing, 102206, China \\ ${ }^{3}$ Beijing Key Laboratory of New Energy and Low-Carbon Development, North China Electric Power University, Beijing, 102206, China
}

\begin{abstract}
With the deepening of power system reform, the precise investment and lean development of power grids have become the focus of power grid enterprises. It is of great significance to carry out evaluation research on the efficiency of input and output of effective assets of power grids. Based on the analysis of the status quo of effective asset evaluation in China's power grid, this paper combines the model of super-efficient DEA with the analysis of effective asset output efficiency of power grid to construct an evaluation system of effective asset input and output efficiency of power grids, and takes the national power grid as an example for calculation and analysis. This paper objectively evaluates the internal and external factors affecting the efficiency of the effective assets of the grid, and provides quantitative analysis support for the effective asset investment decision of the grid.
\end{abstract}

\section{Introduction}

Since March 2015, the document "Several Opinions on the Further Deepening of the Reform of the Power System (Zhongfa [2015] No. 9) has been officially released. The pricing principle of the electricity price has been changed from "the difference of purchase and sales price" to "permitted cost plus granted income". Therefore, it is important to clarify and improve the utilization of effective assets. Although the network DEA [1-2] method is widely used in the field of efficiency evaluation, the application of the super-efficiency DEA model [3-4] is very rare in the field of effective assets of the grid. At present, the super-efficient DEA model is mainly used in agriculture, science and technology and service industries. In summary, this paper will use the super-efficient DEABCC model to analyze the effective assets of the national grid. The rest of this paper unfolds as follows. In Section 2 , we explain the status quo of effective assets of power grids and introduce the definition scope of effective assets in China. In Section 3, we establish an indicator system for effective assets input and output of power grids. Mathematical formulations are presented in Section 4. An application to the national power grid is presented in Section 5, along with analyzed from the perspective of efficiency and projection. Conclusions are given in Section 6.

\section{Status quo of effective asset evaluation of power grid}

\footnotetext{
$\overline{{ }^{*} \text { Corresponding author:274883292@.qq.com }}$
}

With the deepening of the electric power system reform, power grid effective assets will be the main basis on where government or regulatory agency enterprise computes grid grant income and prices the transmissiondistribution price. Therefore, it is of very great importance to define the range of effective assets and evaluate their valuation for grid enterprises. In the Measures for the Determination of Effective Assets of the Power Grid (Temporary), effective assets of the power grid refers to the assets necessary to maintain the continuous and normal production and operation activities of the power grid enterprises, including fixed assets (net value) (included fixed assets formed under construction), current assets, long-term investments, intangible assets, other assets, etc. Before the main and auxiliary separations are not in place, the auxiliary services for the production and operation activities of the grid enterprises are still regarded as effective assets. From Figure 1, we can see that the total assets of China's power grid are rising year by year, but the total profit has not grown steadily and is relatively low. In Figure 2, it can be concluded that the return on equity of the grid is relatively low, even showing negative growth in 2009. And the growth rate has been decreasing year by year in the past five years. Therefore, it is necessary and urgent to study the input-output efficiency of effective assets. 


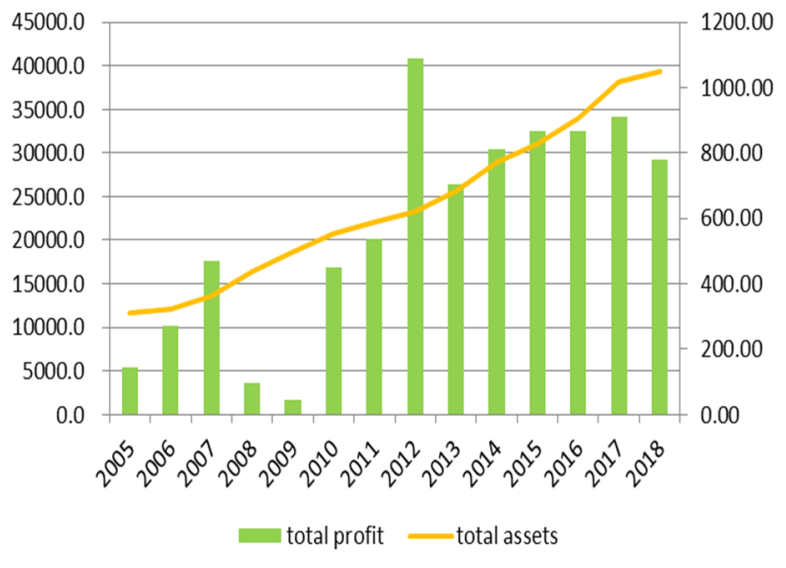

Fig.1The fluctuation of the total profit and total assets in 20052018

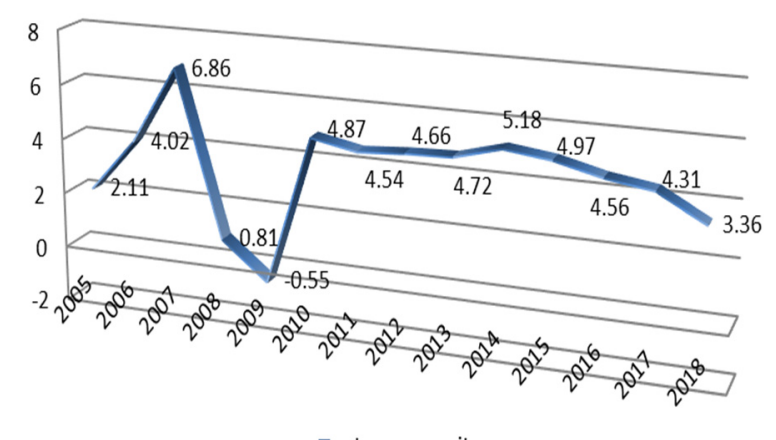

- return on equity

Fig.2The fluctuation of the return on equity in 2005-2018

\section{Grid effective assets input and output efficiency evaluation system}

According to the definition of effective assets, the selected indicators should be related to the main business, and the selected indicators are shown in Figure 3.

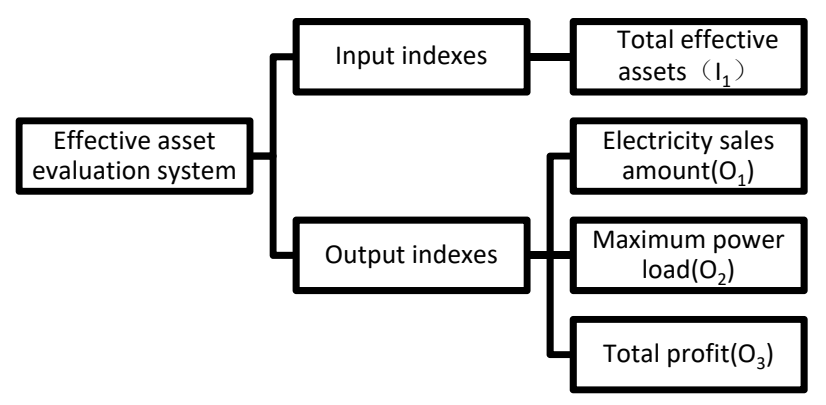

Fig.3 The evaluation system of effective asset

\section{The super-efficient network DEA method}

This paper adopts the super-efficient network DEA-BCC input-oriented model because the super-efficient network DEA can refine the efficiency value of the effective unit compared with the traditional model, better distinguish the difference between the effective units, and carry out more in-depth analysis. For invalid units, the superefficient network DEA is consistent with the calculation results of the traditional model. The BCC model can separate pure technical efficiency and scale efficiency based on the CCR model, so as to more clearly see the reasons for the change in the comprehensive technical efficiency value. The input-oriented model is to reduce the proportion of inputs with the same output, that is, to produce maximum output benefits with the least amount of inputs. The SE-DEA model is defined as follow:

$$
\begin{gathered}
\min \left[\theta-\varepsilon\left(\sum_{i=1}^{m} s_{i}^{-}+\sum_{r=1}^{s} s_{r}{ }^{+}\right)\right] \\
\text {s.t. } \sum_{\substack{j=1 \\
j \neq k}}^{n} \lambda_{j} x_{i j}+s_{i}{ }^{-}=\theta x_{0} \\
\sum_{\substack{j=1 \\
j \neq k}}^{n} \lambda_{j} y_{r j}-s_{r}{ }^{+}=y_{0}
\end{gathered}
$$

$\lambda_{j} \geq 0, j=1,2, \ldots, n, s_{i}{ }^{-} \geq 0, s_{r}{ }^{+} \geq 0, \sum_{\substack{j=1 \\ j \neq k}}^{n} \lambda_{j}=1$

In the equation (1), $n$ is the number of evaluation units, $m$ and $s$ are respectively the input index and the output index, $x_{i j}$ is the $\mathrm{i}$-th input of the $\mathrm{j}$-th DMU, and $y_{r j}$ is the $\mathrm{r}$-th output of the $\mathrm{j}$-th DMU, $\theta$ is the super efficiency evaluation value, $\varepsilon$ is the non-Archimedes infinitesimal quantity greater than zero, $s_{i}^{-}, s_{r}{ }^{+}$are the slack and residual variables of input and output respectively, $\lambda$ is the weight coefficient matrix, $x_{0}, y_{0}$ are the original input and output.

\section{Empirical and results analysis}

\subsection{Data collection}

According to the year, the data of various indicators from 2005 to 2018 are extracted from the State Grid Corporation's Social Responsibility Report. The calculation of effective assets is based on the complete consumption coefficient of input and output of different industries according to the China Statistical Year book.

Table1. Descriptive statistics of input and output variables of effective asset,2005-2018.

\begin{tabular}{ccccc}
\hline Variable & Max & Min & Mean & StDev \\
\hline $\begin{array}{c}\text { Total effective } \\
\text { assets } \mathrm{I}_{1} \\
\begin{array}{c}\text { Electricity } \\
\text { sales }\end{array}\end{array}$ & 27528 & 1989 & 14495 & 7757 \\
$\begin{array}{c}\text { amount } \mathrm{O}_{1} \\
\text { Maximum } \\
\text { power } \\
\text { load } \mathrm{O}_{2}\end{array}$ & 8 & 3 & 5 & 2 \\
Total profit $\mathrm{O}_{3}$ & 1090 & 45 & 575 & 325 \\
\hline
\end{tabular}




\subsection{Input-output analysis}

In this paper, we evaluate the efficiency of effective assets

\begin{tabular}{ccccc}
\hline \multicolumn{5}{c}{ The super-efficient DEA model } \\
\hline year & $\begin{array}{c}\text { comprehensive } \\
\text { technical } \\
\text { efficiency }\end{array}$ & $\begin{array}{c}\text { pure } \\
\text { technical } \\
\text { efficiency }\end{array}$ & $\begin{array}{c}\text { scale } \\
\text { efficiency }\end{array}$ & rank \\
\hline 2005 & 0.89 & 1.04 & 0.86 & 3 \\
2006 & 1.67 & 1.73 & 0.96 & 1 \\
2007 & 0.41 & 0.54 & 0.77 & 12 \\
2008 & 0.24 & 0.46 & 0.53 & 14 \\
2009 & 0.24 & 0.52 & 0.46 & 13 \\
2010 & 0.28 & 0.71 & 0.40 & 11 \\
2011 & 0.32 & 0.87 & 0.37 & 8 \\
2012 & 0.65 & 1 & 0.65 & 4 \\
2013 & 0.38 & 1.23 & 0.31 & 2 \\
2014 & 0.39 & 0.89 & 0.44 & 7 \\
2015 & 0.30 & 0.74 & 0.41 & 10 \\
2016 & 0.28 & 0.85 & 0.32 & 9 \\
2017 & 0.26 & 1 & 0.26 & 4 \\
2018 & 0.22 & 1 & 0.22 & 4 \\
\hline
\end{tabular}

of power grid from 2005 to 2018 through DEA-SOLVER Pro5.0 software, we not only obtain integrated technical efficiency, pure technical efficiency and scale efficiency, but also get the optimal target value and potential commission space.

\subsubsection{Analysis of efficiency values}

First, according to the super-efficient DEA model, the super-efficient comprehensive technical efficiency of effective assets in 2006 is 1.67 , which means that the utilization of effective assets in that year increases by $67 \%$. The relative efficiency is still valid, and it's the best state when the efficiency value is 1 at this time.

In addition, from Figure.4, we see that the efficiency of the integrated technology fluctuates greatly. 2006 witnessed the rapid development of the main business of the State Grid. The scale of the power grid continued to expand and the capacity of power grid resources was continuously improved. As of 2006, cross-transmission capacity had increased by $38.4 \%$. At the same time, State Grid Corporation was still strengthening the technical transformation of the power grid, accumulating a total transmission capacity of 85.27 million kilowatts. As a result, effective asset utilization has risen sharply. In 2018, the comprehensive efficiency value is the lowest, because the growth rate of the main business of the power grid is much lower than the growth rate of the main business in 2006.

Finally, for other units whose comprehensive efficiency value does not reach 1 (invalid evaluation unit), the overall scale efficiency is low, indicating that the scale utilization benefit of effective assets in the country has not reached the most effective, and there is still a lot of room for improvement. However, the overall technical efficiency is higher than the overall scale efficiency, indicating that effective assets are well utilized in the management process. There are other units whose pure technical efficiency value does not reach 1 , indicating that it is still necessary to optimize the input structure.

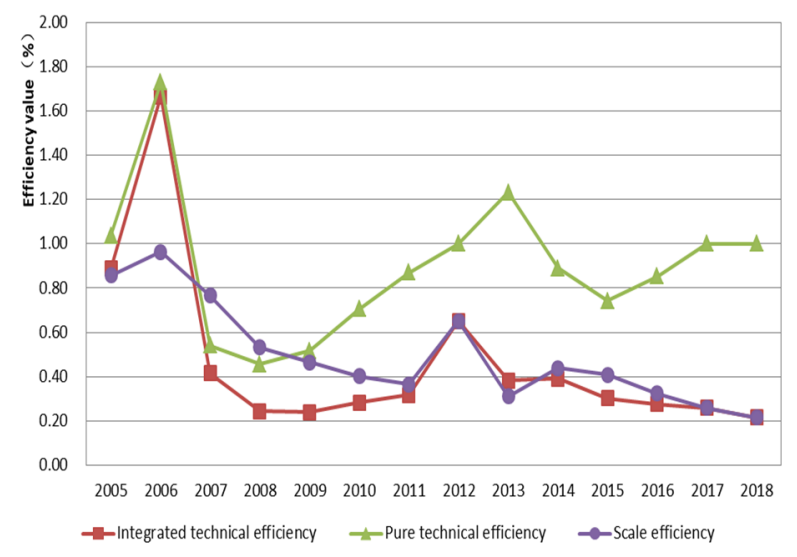

Fig.4 The results of effective asset efficiency value,2005-2018

Table.2 The results of effective asset efficiency value in the super-efficient DEA model,2005-2018

\subsubsection{Projection Analysis}

The comprehensive technical efficiency of effective assets in 2006 was 1.67. Therefore, when the input of effective assets increase by 3433.23 , the electricity sales will increase by 17313.9 , and the effective value will be 1. In other years, the effective assets are redundant and have great potential for improvement. Among them, the comprehensive technical efficiency is the lowest in 2018, and the effective asset redundancy is the most. Therefore, it is urgent to establish a reasonable effective asset management system and make a rational plan configure effective assets.

\section{Conclusion}

This article uses the super-efficiency DEA - CCR model to compare the input and output efficiency of nationwide effective asset of power grids from 2005 to 2018. Through the above calculations, effective assets occupy a large proportion in the State Grid Corporation, but it is redundancy, very low efficiency and poor profitability. According to relevant statistics, in the revenue structure of the State Grid Corporation, transmission and distribution revenue accounts for more than $90 \%$, but the profitability is the lowest, with a net interest rate of about $2 \%$. Electrical equipment, clean energy and energy saving sectors are the most profitable sectors of the company. For example, the net profit margin of energy saving projects in the distribution network is more than $15 \%$ [5]. Therefore, in order to ensure the efficient operation of effective assets, it is necessary to establish a reasonable management and operation system, such as reducing the idleness of assets, developing leasing business, and accelerating asset turnover. 
This work has been supported by the Science and Technology Project of State Grid Jibei Electric Power Company Limited "Research on evaluation method of effective assets input-output of power grid”.

\section{References}

1. Charnes A., Cooper W.W and Rhodes E., European J. Oper. Res., Measuring the efficiency of decision making units, 2, 429-444 (1978).

2. Banker RD., Charnes A and Cooper W.W., Mana. Sci., Some Models for Estimating Technical and Scale Inefficiencies in Data Envelopment Analysis, 9, 30 (1984).

3. Banker RD and Gifford J.L., A relative efficiency model for the evaluation of public health nurse productivity. 535-538 (1988).

4. Banker RD., Das and Datar S.M., Research in Governmental and Nonprofit Accounting, Analysis of cost variances for management control in Hospitals, 5, 269-291 (1989).

5. X.Q. Wang, Energy, Breaking the old and new: From the perspective of investment, the value and logic of power system reform, 7, 74-79 (2018). 